\title{
Novel Synthesis, Characterization, and Physical Properties of Self-Doped Sulfonated Polyaniline by Copolymerization between $p$-Aminodiphenylamine and o-Aminobenzenesulfonic Acid
}

\author{
Naonori OHNo, Hung-Jen WANG, ${ }^{*}$ Hu YAN, and Naoki ToshimA ${ }^{\dagger}$ \\ Department of Materials Science and Engineering, Science University of Tokyo \\ in Yamaguchi, Onoda-shi, Yamaguchi 756-0884, Japan \\ * Department of Applied Chemistry, School of Engineering, The University of \\ Tokyo, Hongo, Bunkyo-ku, Tokyo 113-8656, Japan
}

(Received September 5, 2000; Accepted October 24, 2000)

\begin{abstract}
Sulfonated polyaniline has been synthesized by a novel method, in which $p$-aminodiphenylamine $(p$ APA) and $o$-aminobenzenesulfonic acid (o-ABS) are copolymerized. The copolymers produced have the same composition even though the feed ratios ( $p$-APA/o-ABS) are varied. This fact as well as the results of elemental analysis, infrared (IR), ultraviolet-visible (UV-Vis), ${ }^{1} \mathrm{H}$ nuclear magnetic resonance (NMR), and X-Ray photoelectron spectroscopic (XPS) spectra show that the copolymer has a so-called one-to-one structure of $p$-APA and $o$-ABS. XPS spectra reveal that three kinds of nitrogen atoms exist in the copolymer, namely, amine nitrogen, radical cation type nitrogen, and iminium ion type nitrogen. One third of the whole nitrogens is self-doped. Conductivity of the copolymer is independent of $\mathrm{pH}$, but lower than that of doped polyaniline probably because of the presence of sulfonyl acid groups. The copolymer is soluble in an aqueous alkaline solution owing to sulfonyl acid groups. Electronic spectra of the mixtures of $p$-APA and $o$-ABS suggest that the $1: 1$ charge-transfer complex is formed between $p$-APA and $o$-ABS. Oxidizing agents are considered to react with the charge-transfer complex to form the one-to-one copolymer of $p$-APA and $o$-ABS.

KEY WORDS Water-Soluble Conductive Polymer / Self-Doped Sulfonated Polyaniline / $p$-Aminodiphenylamine / o-Aminobenzenesulfonic Acid / Charge-Transfer Complex / Copolymer / Good Processability /
\end{abstract}

Among the aromatic conductive polymers such as polyacetylene, polythiophene, polyaniline, and polypyrrole, polyaniline has been most successfully applied to practical use, since it is stable under air and soluble in solvents such as $N$-methyl-2-pyrrolidone (NMP). For example, the applications to antistatic agents, electromagnetic shielding materials, secondary batteries, ${ }^{1-3}$ redox reaction catalysts, ${ }^{4-6}$ gas sensors, ${ }^{7}$ gas separation membranes, ${ }^{8}$ artificial mascle, ${ }^{9}$ etc. have been examined. However, there are still big problems in processability of polyaniline.

The attempts to improve processability by means of altering polyaniline into its derivatives by introducing alkyl groups into the aromatic ring and/or the nitrogen site were reported so often. ${ }^{10-12}$ However, this introduction always causes the decrease of electric conductivity in compensation for increase of processability. In the meantime, the precursor method was reported on processing of polyphenylene for the purpose of improving processability. ${ }^{13}$ In this method a film of polyphenylene was obtained by heating a film of the precursor having good processability. However, there was no reports on the application of the precursor method to prepare a polyaniline film. Recently we have succeeded in preparing a film of polyaniline by heating a cast film of polyanthranilic acid which is a soluble precursor of polyaniline. ${ }^{14-15}$

On the other hand, much attention has been paid to sulfonated polyanilines, ${ }^{16-34}$ because it is stable and soluble even into water when self-doped. In a conventional method, sulfonated polyaniline was prepared by the re-

\footnotetext{
${ }^{\dagger}$ To whom correspondence should be addressed.
}

action of the emeraldine base form of polyaniline with fuming sulfuric acid. ${ }^{16,19-21}$ However, control of the reaction in this method seems to be difficult in case of mass production. It was also reported that $o$ aminobenzenesulfonic acid (o-ABS) could not be directly polymerized by using an oxidizing agent such as ammonium persulfate. ${ }^{16}$

Recently sulfonated polyanilines were prepared by copolymerization of aniline and sulfonated aniline instead of sulfonation of emeraldine base with fuming sulfuric acid. For example the copolymers between aniline and $o$ ABS, ${ }^{31} \quad o$-alkoxysulfonated anilines, ${ }^{33}$ and $N$ propylbenzenesulfonic acid-aniline $\mathrm{e}^{34}$ have been reported. Since aniline dimer, namely $p$-aminodiphenylamine ( $p$ APA) is more reactive than aniline, we have examined in this paper to copolymerize not aniline but $p$-APA with $o$ ABS. The experiments have revealed the interesting results that the copolymerization occurs via the formation of one-to-one charge-transfer complex of $p$-APA and $o$ ABS and produces $1: 1$ copolymer of $p$-APA and $o$-ABS. Details of the novel synthetic method of sulfonated polyaniline, its polymerization mechanism, and physical properties of the resulting copolymer are reported.

\section{EXPERIMENTAL}

\section{Materials}

$p$-APA and $o$-ABS were purchased from Tokyo Kasei Kogyo Co., Ltd. NMP, ammonium persulfate, and $1 \mathrm{~mol}$ $\mathrm{dm}^{-3} \mathrm{HCl}$ and $0.1 \mathrm{~mol} \mathrm{dm}{ }^{-3} \mathrm{NaOH}$ solutions were purchased from Wako Pure Chemical Industries, Ltd. All reagents were used as received. 
N. OHNo et al.

Table I. Copolymerization of $p-\mathrm{APA}$ and $o-\mathrm{ABS}^{\mathrm{a}}$

\begin{tabular}{|c|c|c|c|c|c|c|c|c|c|}
\hline \multirow{2}{*}{ Run } & \multicolumn{2}{|c|}{$p$-APA } & \multicolumn{2}{|c|}{$o-\mathrm{ABS}$} & \multirow{2}{*}{$\frac{p-\mathrm{APA} / o-\mathrm{ABS}}{\text { mole ratio }}$} & \multirow{2}{*}{$\begin{array}{c}\text { Reaction } \\
\text { Time/h }\end{array}$} & \multicolumn{3}{|c|}{ Yield } \\
\hline & $\mathrm{g}$ & $\mathrm{mmol}$ & $\mathrm{g}$ & $\mathrm{mmol}$ & & & g & wt\% ${ }^{b}$ & $\mathrm{wt} \%{ }^{\mathrm{c}}$ \\
\hline 1 & 1.060 & 5.76 & 0.000 & 0.00 & $1 / 0$ & 24 & 1.050 & 99 & \\
\hline 2 & 0.530 & 2.88 & 0.500 & 2.88 & $1 / 1$ & 24 & 0.797 & 77 & 77 \\
\hline 3 & 0.530 & 2.88 & 1.000 & 5.76 & $1 / 2$ & 24 & 0.856 & 56 & 83 \\
\hline 4 & 0.530 & 2.88 & 1.500 & 8.64 & $1 / 3$ & 24 & 0.875 & 43 & 85 \\
\hline 5 & 0.530 & 2.88 & 2.000 & 11.52 & $1 / 4$ & 24 & 0.875 & 32 & 85 \\
\hline 6 & 0.530 & 2.88 & 0.500 & 2.88 & $1 / 1$ & 15 & 0.787 & 76 & \\
\hline 8 & 0.530 & 2.88 & 0.500 & 2.88 & $1 / 1$ & 2 & 0.772 & 75 & \\
\hline
\end{tabular}

${ }^{\mathrm{a}}$ Oxidizing agent, $\left(\mathrm{NH}_{4}\right)_{2} \mathrm{~S}_{2} \mathrm{O}_{8}$; Reaction temperature, $40^{\circ} \mathrm{C} .{ }^{\mathrm{b}}$ Weight percentage of polymer $(\mathrm{g})$ per charged monomers (g). ${ }^{\mathrm{c}}$ Weight percentage of polymer $(\mathrm{g})$ per $1.030 \mathrm{~g}$ of monomers $(0.530 \mathrm{~g}$ of $p$-APA and $0.500 \mathrm{~g}$ of $o$-ABS).

\section{Measurements}

Fourier transformed infrared (FT-IR) spectra were recorded as a $\mathrm{KBr}$ disk, using a JEOR JIR-WINSPEC 50 spectrometer. Ultraviolet-visible (UV-Vis) spectra were taken on a Shimadzu UV-3100 PC spectrophotometer. ${ }^{1} \mathrm{H}$ Nuclear magnetic resonance $\left({ }^{1} \mathrm{H}\right.$ NMR) spectra were measured using a JEOL JNM-EX 270 spectrometer (270 $\mathrm{MHz}$ for $\left.{ }^{1} \mathrm{H}\right)$ in dimethyl sulfoxide- $d_{6}\left(\mathrm{DMSO}-d_{6}\right)$ at room temperature. X-Ray photoelectron spectroscopic (XPS) analysis was performed with a Kratos AXIS-HS spectrometer using an $\mathrm{Mg}-K_{\alpha}$ radiation source at a base pressure of $10^{-9}$ Torr. Thermal analysis was carried out with a Mac Science WS 002 thermal analyzing system. Approximately $2 \mathrm{mg}$ of the sample was heated at a heating rate of $10^{\circ} \mathrm{C} \mathrm{min}{ }^{-1}$ under air. The molecular weight measurement was carried out on a Shimadzu LC-10 AD gel permeation chromatography (GPC) analyzing system with a Shodex KD-806 M column $(8 \times 300 \mathrm{~mm})$. To perform the GPC measurement, $c a$. $0.01 \mathrm{wt} \% N$-methyl-2pyrrolidone (NMP) (containing $0.1 \mathrm{wt} \% \mathrm{LiCl}$ ) solutions of the polymers were prepared and passed through a 0.5 $\mu \mathrm{m}$ filter prior to injection. A column oven was set at $60^{\circ} \mathrm{C}$. The carrier solvent was $N$-methyl-2-pyrrolidone (NMP) containg $0.1 \mathrm{wt} \% \mathrm{LiCl}$ and its flow rate was 0.5 $\mathrm{cm}^{3} \mathrm{~min}^{-1}$. The wave length of a UV-Vis detector was set at $302 \mathrm{~nm}$. The electric conductivity was measured for a pressed-pellet type sample of $10 \mathrm{~mm}$ in diameter and $c a .1 \mathrm{~mm}$ in thickness with a Takahashi Seiki conductivity measuring device by a four-probe technique. Elemental analyses were carried out by Shonan Bunseki Center Co., Ltd.

\section{Synthesis of Poly(o-APA-co-p-ABS)}

A typical synthetic method is as follows: $0.53 \mathrm{~g}(2.88$ mmol) of $p$-APA and $0.50 \mathrm{~g}(2.88 \mathrm{mmol})$ of $o$-ABS were added into a $300 \mathrm{~cm}^{3}$ eggplant type flask and dissolved in $50 \mathrm{~cm}^{3}$ of deionized water. The flask was then placed in a constant temperature bath at $40^{\circ} \mathrm{C}$. In another beaker a solution of $0.66 \mathrm{~g}(2.88 \mathrm{mmol})$ of ammonium persulfate in $50 \mathrm{~cm}^{3}$ of deionized water was prepared, and added dropwise into the mixtures of $p$-APA and $o$ ABS with stirring in $15 \mathrm{~min}$. The polymerization was carried out by stirring the mixtures for $24 \mathrm{~h}$. After filtration the precipitate was washed with water and acetone, and dried in vacuo for $12 \mathrm{~h}$ at $60^{\circ} \mathrm{C}$. The crude polymer

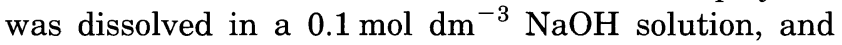
then reprecipitated with $1 \mathrm{~mol} \mathrm{dm}{ }^{-3} \mathrm{HCl}$. The yield of pure polymer was $0.80 \mathrm{~g}$ ( $77 \%$ yield).

\section{Measurement of Complex Formation between p-APA and $o-A B S$}

The solutions of $p$-APA and $o$-ABS in water/ethanol $(1: 1, \mathrm{v} / \mathrm{v})$ were prepared at the various mole ratios of $p$ APA to $o$-ABS of $0 / 1,1 / 9,1 / 3,1 / 1,3 / 1,9 / 1$, and 1/0. The total molar concentration of $p$-APA and $o$-ABS was kept constant at $0.02 \mathrm{~mol} \mathrm{dm}^{-3}$. UV-Vis spectroscopy measurement was carried out for these solutions in order to clarify the complex formation between $p$-APA and $o$ ABS by the method of continuous variations according to Job. ${ }^{35-36}$

\section{RESULTS AND DISCUSSION}

\section{Copolymerization of $p-A P A$ and $o-A B S$}

Copolymerization of $p$-APA and $o$-ABS was examined at various monomer ratios ( $p$-APA / $o-\mathrm{ABS}$ ) by using ammonium persulfate as an oxidant (Table I). In the homopolymerization of $p$-APA the polymer was obtained at high yield of $99 \%$, when the yield (\%) was defined as a weight percentage of the isolated polymer (g) per charged monomer $(\mathrm{g})$. In the copolymerization of $p$-APA and $o$-ABS the polymer yield in percentage decreases, but the absolute yield is nearly constant when the quantity of $o$-ABS is increased and that of $p$-APA is kept constant. If the copolymerization occurs at $1: 1$ mole ratio between $p$-APA and $o$-ABS regardless of the feed ratio of the monomers, then the excess $o$-ABS does not contribute to the copolymerization. Thus, if the percentage yield of the copolymer is calculated based on $0.530 \mathrm{~g}(2.88$ mmol) of $p$-APA and the same moles $(2.88 \mathrm{mmol}=0.500$ g) of $o$-ABS, then the weight percent yield from run 2 to 5 is almost constant from $77 \%$ to $85 \%$, as shown in the last column of Table I. This fact indicates that the copolymerization of $p$-APA and $o$-ABS proceeds at $1: 1$ mole ratio. In addition, the yield of run 2 and those from run 6 to run 8 are nearly the same, even if the reaction time was shortened from $24 \mathrm{~h}$ to $2 \mathrm{~h}$. This shows that the copolymerization is almost completed in $2 \mathrm{~h}$.

\section{Elemental Analysis}

The results of elemental analysis of copolymers are shown in Table II. The composition formulae of copolymers, determined on the basis of elemental analyses, are $\mathrm{C}_{21.0} \mathrm{H}_{21.0} \mathrm{~N}_{3.4} \mathrm{~S}_{1.0} \mathrm{O}_{4.3}, \mathrm{C}_{20.0} \mathrm{H}_{18.4} \mathrm{~N}_{3.0} \mathrm{~S}_{1.0} \mathrm{O}_{4.6}$, and $\mathrm{C}_{18.7} \mathrm{H}_{18.4^{-}}$ $\mathrm{N}_{2.8} \mathrm{~S}_{1.0} \mathrm{O}_{5.2}$, in the case of $1 / 1,1 / 2$, and $1 / 4$ of the charged molar ratio of $p$-APA to $o$-ABS, respectively. When these composition formulae are compared with $\mathrm{C}_{18} \mathrm{H}_{15} \mathrm{~N}_{3} \mathrm{SO}_{3}$, the calculated formula for the $1: 1$ copolymer of $p$-APA 
Table II. Elemental analysis of copolymer

\begin{tabular}{ccccccc}
\hline \multirow{2}{*}{$\begin{array}{c}\text { Charged mole ratio } \\
p \text {-APA/o-ABS }\end{array}$} & $\mathrm{C}$ & $\mathrm{H}$ & $\mathrm{N}$ & $\mathrm{S}$ & $\mathrm{O}^{\text {a }}$ & \multicolumn{2}{c}{ Mole ratio } \\
\cline { 2 - 5 } N/S & 3.37 & \\
$1 / 1$ & 59.87 & 5.03 & 11.23 & 7.61 & 16.26 & 3.02 \\
$1 / 2$ & 58.93 & 4.54 & 10.39 & 7.87 & 18.27 & 2.84 \\
Calc. $^{\mathrm{b}}$ & 56.45 & 4.63 & 9.97 & 8.01 & 20.94 & 3.00 \\
\hline
\end{tabular}

${ }^{a}$ By difference. ${ }^{\text {b }}$ Calc. for $\mathrm{C}_{18} \mathrm{H}_{15} \mathrm{~N}_{3} \mathrm{SO}_{3}$.

and $o$-ABS, the proportion of $\mathrm{H}$ and $\mathrm{O}$ is always a little bigger than the calculated ones. This seems to be attributed to the contaminated water. The proportions of $\mathrm{N}$ to $\mathrm{S}$ in mole ratio are almost 3.0 and fixed, even if the charged mole ratio is varied. Thus, one atom of S corresponds to three atoms of $\mathrm{N}$ in all copolymers. In other words, it can be concluded that $p$-APA and $o$-ABS can make a $1: 1$ copolymer based on the results of elemental analyses. Fan et al. reported in the copolymerization between aniline and $o$-ABS that the increase of fraction of $o$-ABS in the reaction mixture causes the increase of fraction of $o$-ABS structure unit in the copolymer. ${ }^{31}$ However, the increase of fraction of $o$-ABS structure unit in the copolymer is from 0.30 to 0.36 in the increase from 0.5 to 0.75 of fraction of $o-A B S$ in the reaction mixture. It is interesting for us that these values may be considered to be almost constant, although they did not mention so.

\section{Infrared Spectroscopy (IR)}

The homopolymer of $p$-APA reveals nearly the same IR spectrum of polyaniline reported. ${ }^{37-38}$ In contrast, the IR spectrum of the copolymer has strong asymmetric and symmetric $\mathrm{S}=\mathrm{O}$ stretching bands at 1023 and 1081 $\mathrm{cm}^{-1}$, respectively, in addition to bands attributed to polyaniline. IR spectra of copolymers prepared at various charged mole ratios of $p$-APA to $o$-ABS are shown in Figure 1. In Figure 1 the intensity of the $\mathrm{S}=\mathrm{O}$ stretching bands does hardly change, even if the charged mole ratio of $p$-APA to $o-\mathrm{ABS}$ is varied. This means that the structure of copolymers is almost the same independent of the charged mole ratio.

\section{Electronic Spectroscopy}

The electronic spectra were measured about copolymer of $p$-APA and $o$-ABS $(1: 1)$ in NMP and a $0.1 \mathrm{~mol}$ $\mathrm{dm}^{-3} \mathrm{NaOH}$ aqueous solution, in addition to that of polyaniline in NMP. The copolymer in NMP has the absorption maximum due to quinoid rings at about 580 $\mathrm{nm}$, which is the same as that of polyaniline. The $\pi \rightarrow \pi^{*}$ transition due to benzenoid rings, on the other hand, reveals a hypsochromic shift from $303 \mathrm{~nm}$ for polyaniline to $301.5 \mathrm{~nm}$ for the copolymer. This hypsochromic shift seems to be attributed to the decreasing extent of conjugation in polymer backbones caused by the increasing benzenoid ring torsion angle due to sulfonic acid groups of copolymer. ${ }^{19}$ The absorption peak at $580 \mathrm{~nm}$ of the copolymer in NMP shifts to $531 \mathrm{~nm}$ in an $\mathrm{NaOH}$ aqueous solution which is more polar solvent than NMP. The absorption maximum of the copolymer at $292 \mathrm{~nm}$ in a 0.1 mol $\mathrm{dm}^{-3} \mathrm{NaOH}$ aqueous solution is attributed to $\pi \rightarrow$ $\pi^{*}$ transition of benzenoid rings and the absoption peak at $531 \mathrm{~nm}$ is ascribed to exciton transition of quinoid

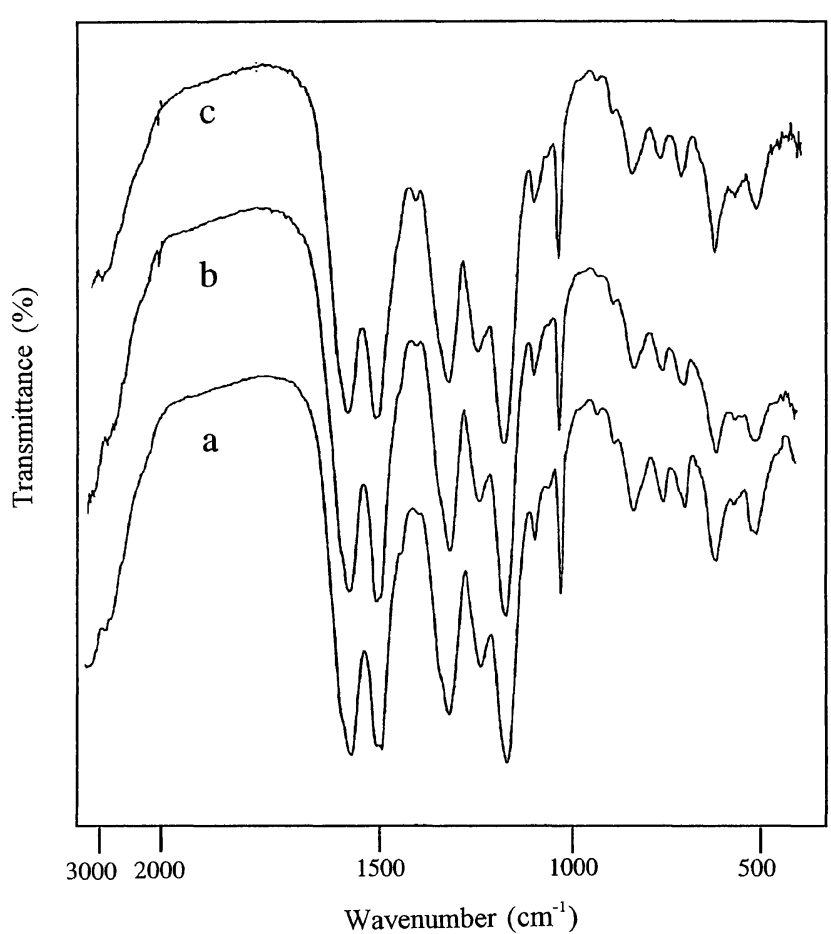

Figure 1. IR spectra of copolymers at various feed mole ratios of $p$-APA to $o$-ABS of (a) $1 / 2$, (b) $1 / 4$, and (c) $1 / 8$.

rings. It was observed that the absorption maximum at $531 \mathrm{~nm}$ in $\mathrm{NaOH}$ aq. reveals a bathochromic shift when NMP is added to the solution. This is considered that the backbone of copolymer is changed from coil-like conformation to more planar conformation in NMP which is a less polar solvent than an $\mathrm{NaOH}$ aqueous solution. The same phenomenon was previously reported on the sulfonated polyaniline which was synthesized by sulfonation of emeraldine base by fuming sulfuric acid. ${ }^{19}$ In addition, it is obvious that the present product is copolymer, and not mixtures of polyaniline and sulfonated polyaniline because of the complete solubility of the product in an aqueous alkaline solution.

${ }^{1} \mathrm{H}$ Nuclear Magnetic Resonance Spectroscopy $\left({ }^{1} \mathrm{H}\right.$ NMR)

Measurement of ${ }^{1} \mathrm{H}$ NMR was performed after the copolymer of $p$-APA and $o$-ABS $(1: 1)$ was dissolved into DMSO $-d_{6}$ and the contaminating water was removed from the solution with molecular sieves (for $24 \mathrm{~h}$ ). The ${ }^{1} \mathrm{H}$ NMR spectrum of copolymer is shown in Figure $2 \mathrm{c}$, and those of $p$-APA and $o$-ABS in Figure $2 \mathrm{a}$ and $2 \mathrm{~b}$, respectively. Comparison of these ${ }^{1} \mathrm{H}$ NMR spectra suggests that peaks at $6.40-7.35 \mathrm{ppm}$ and at $7.35-7.80$ $\mathrm{ppm}$ in Figure 2c can be ascribed to the $p$-APA unit and to the $o$-ABS unit of the copolymer, respectively. As a 


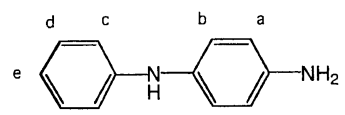

(a)
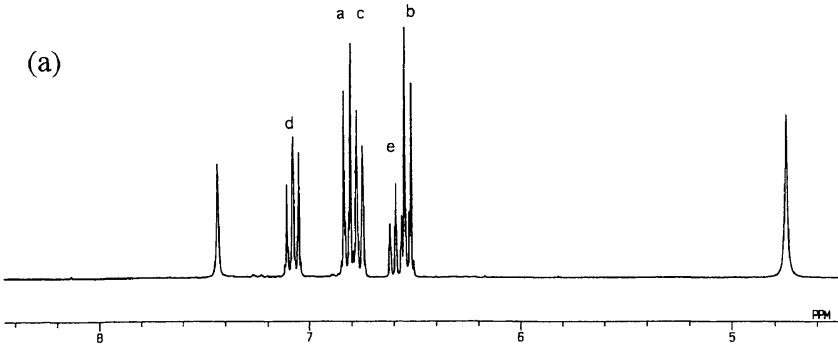

(b)
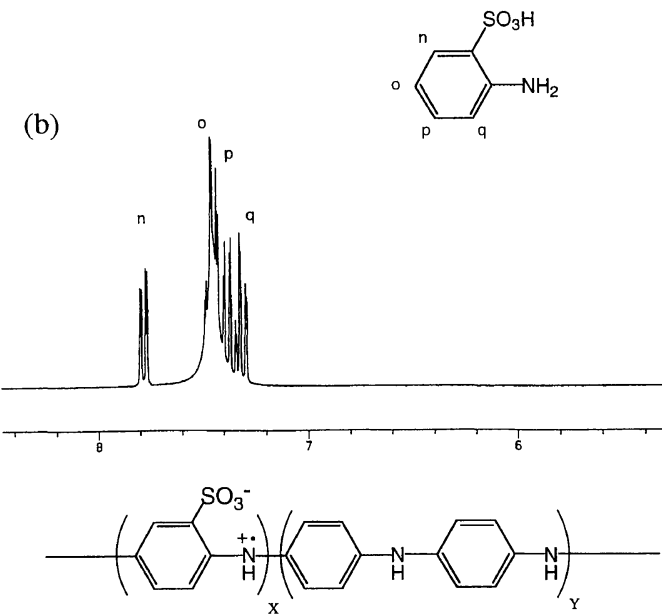

(c)

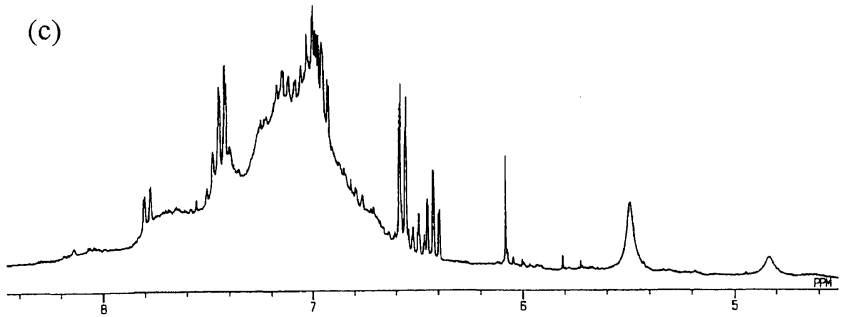

Figure 2. ${ }^{1} \mathrm{H}$ NMR spectra of $p$-APA, $o$-ABS, and copolymer of $p$ $\mathrm{APA}$ and $o$-ABS.

matter of fact, the ratio of the integrated intensity of peaks at $7.35-7.80 \mathrm{ppm}$ to those at $6.40-7.35 \mathrm{ppm}$ is 3 : 8.5 , which is close to the theoretical ratio $(3: 8)$ of the 1 : 1 copolymer of $p$-APA and $o$-ABS. High molecular weight of the copolymer, as well as some radical species in the aniline unit of the copolymer, may cause broadening of ${ }^{1} \mathrm{H}$ NMR peaks.

\section{$X$-Ray Photoelectron Spectroscopy (XPS)}

The XPS spectrum of copolymer of $p$-APA and $o$-ABS $(1: 1)$ is shown in Figure 3 . The $\mathrm{N}(1 \mathrm{~s})$ spectrum of copolymer can be deconvoluted into three Gaussian component peaks, centered at $399.4 \mathrm{eV}$ with a fwhm (full width at half maximum) of $1.6 \mathrm{eV}$, at $400.2 \mathrm{eV}$ with a fwhm of $1.9 \mathrm{eV}$, and at $401.9 \mathrm{eV}$ with a fwhm of $1.9 \mathrm{eV} .^{27}$ The area intensities of these three peaks are about $65 \%$, $30 \%$, and $5 \%$, respectively. These three peaks are assigned as follows; $399.4 \mathrm{eV}$ for amine nitrogen (-NH-), $400.2 \mathrm{eV}$ for radical cation $\left(\mathrm{N}^{+}\right)$, and $401.9 \mathrm{eV}$ for iminium ion $\left(-\mathrm{NH}^{+}=\right)$. The nitrogens of radical cation and iminium ion occupy about one third of the whole nitrogens. These nitrogens would be ascribed to the quinoid

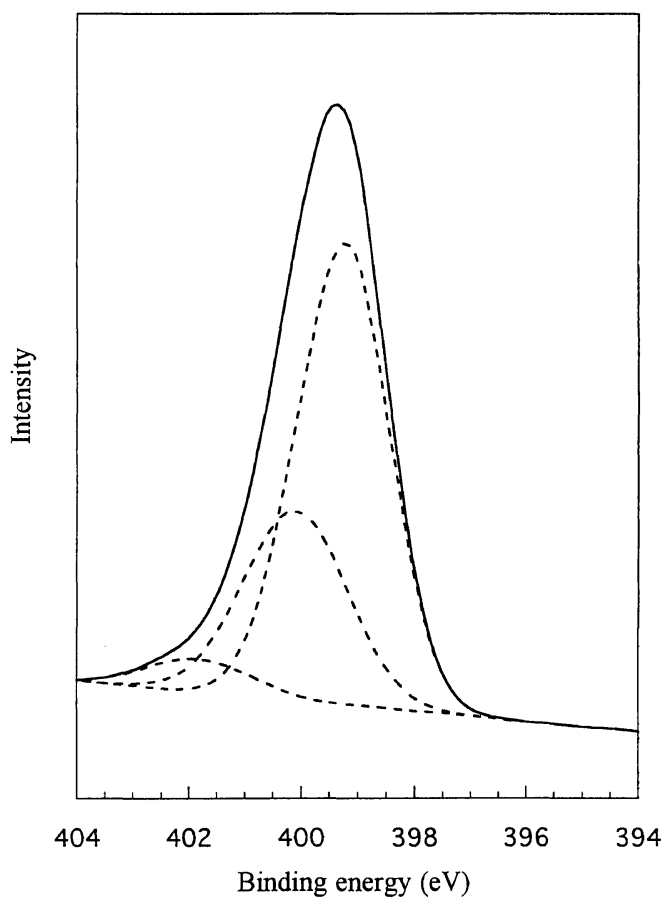

Figure 3. XPS spectrum of the $1: 1$ copolymer of $p$-APA and $o$ ABS.

structure generated by self-doping with protons of sulfonic acid groups. In addition, the peak at $398.2 \mathrm{eV}$ with a fwhm of $1.6 \mathrm{eV}$, corresponding to the nitrogen of nonprotonated quinoid unit, is not observed in Figure 3. This observation indicates that all the quinoid units of copolymer are completely self-doped. This is consistent with the previous conclusion that the produced polymer has the structure of $1: 1$ copolymer. The results of elemental analysis reveal also that the residual oxidizing agent $\mathrm{NH}_{4}^{+}(403 \mathrm{eV})$ is $3.3 \%$ or less in copolymer.

\section{Thermogravimetric Analysis (TGA)}

The TGA measurement of copolymer of $p$-APA and $o$ ABS $(1: 1)$ reveals about $2 \%$ of a weight loss at $100^{\circ} \mathrm{C}$, which is considered to be due to elimination of water. The presence of some water in the copolymer is also suggested by the higher $\mathrm{H}$ and $\mathrm{O}$ contents in the copolymer than the calculated ones in elemental analysis. A weight loss $(20 \%)$ at about $300^{\circ} \mathrm{C}$ is ascribed to the elimination of some sulfonic acid groups. ${ }^{27}$ At about $500^{\circ} \mathrm{C}$ the copolymer begins to decompose.

Molecular Weight of Copolymer of p-APA and o-ABS (1:1)

Molecular weight of the copolymer was measured by gel permeation chromatography (GPC). Weight-average molecular weight $\left(\bar{M}_{\mathrm{w}}\right)$ of the copolymer is about 3500 . The polydispersity defined as the ratio of weight-average molecular weight $\left(\bar{M}_{\mathrm{w}}\right)$ to number-average molecular weight $\left(\bar{M}_{\mathrm{n}}\right)$ is 1.16 . This means very narrow distribution in molecular weight.

Prévost et al. reported that the number-average molecular weight and the polydispersity of the copolymer between aniline and 1-(o-aminophenoxy)butane-4sulfonic acid are 2204 and 2.2 , respectively, at charged mole fraction of aniline of $0.5 .^{33}$ According to Fan et al., the lower degree of sulfonation for the copolymer of ani- 
line and $o-\mathrm{ABS}$ is due to the low reactivity of $o-\mathrm{ABS}$ in the copolymerization. ${ }^{31}$ Relatively low molecular weight of our copolymer of $p$-APA and $o$-ABS is probably attributed to this low reactivity of $o$-ABS. In contrast, since $p$ APA has higher reactivity than $o$-ABS, our polymerization rather easily proceeds, giving the copolymer with moderate molecular weight. This could be attributed to the high reactivity of $p$-APA as well as the special copolymerization mechanism described later.

\section{Electric Conductivity}

Conductivity of the copolymer of $p$-APA and $o$-ABS ( 1 : 1) was measured by a four-probe technique at room temperature. Conductivities of the copolymer doped with $\mathrm{HCl}$ at $\mathrm{pH} 1,3,5$, and 7 are $5.61 \times 10^{-5}, 3.18 \times 10^{-5}, 3.66$ $\times 10^{-5}$, and $2.63 \times 10^{-5} \mathrm{~S} \mathrm{~cm}^{-1}$, respectively. This result indicates that conductivity of the copolymer is not so much affected by $\mathrm{pH}$ and almost constant probably because of the lack of quinoid structures in the copolymer, as shown by XPS (N (1s) $398.2 \mathrm{eV})$. Fan et al. reported that the conductivity of the copolymer of aniline and $o$ ABS is slightly dependent on $\mathrm{pH}$ in the $\mathrm{pH}$ range of 0 3. ${ }^{31}$ This phenomenon was explained by that small amounts of the imine nitrogen atoms change to radical cations caused by an external Brönsted acid, since the degree of sulfonation of their copolymer is low. However, our copolymer between $p$-APA and $o$-ABS does not show $\mathrm{pH}$ dependence, because quinoid structure units are completely self-doped as shown by XPS analysis.

In addition, owing to electron-withdrawing capability and steric hindrance of the sulfonyl acid group, conductivity of the copolymer is lower than that of dopedpolyaniline. When these self-doped copolymers were further doped by treatment with $\mathrm{I}_{2}$ for $24 \mathrm{~h}$, the conductivities increase up to $2.76 \times 10^{-4}, 6.75 \times 10^{-5}, 1.40 \times 10^{-4}$, and $9.86 \times 10^{-5} \mathrm{~S} \mathrm{~cm}^{-1}$, respectively.

\section{Mechanism of $1: 1$ Copolymerization of $p-A P A$ and $o-$ $A B S$}

The mechanism of copolymerization of $p$-APA and $o$ ABS was studied by the method of continuous variations according to Job. ${ }^{35-36}$ Electronic spectra of $p$-APA, $o$ $\mathrm{ABS}$, and mixtures of those at the various mole ratios of $o$-ABS to $p$-APA, keeping the total molar concentration constant, are shown in Figure 4. The absorption peaks at about $482 \mathrm{~nm}$ and $568 \mathrm{~nm}$ for $p$-APA are observed, while the spectrum for $o$-ABS exhibits no absorption peak over $350 \mathrm{~nm}$. In the mixed aqueous solution of $p$-APA and $o-$ ABS a new broad absorption peak appears at about 588 nm. Figure 5 shows the correlation between the intensity of this new peak at $588 \mathrm{~nm}$ and the mole ratio of $o$ $\mathrm{ABS}$ in the mixtures. Figure 5 reveals that the intensity of the peak at $588 \mathrm{~nm}$ is highest when the mole ratio of $o$-ABS to $p$-APA is $1: 1$, although the plots stray away a little from the triangle which connects $0 \%$ of lateral axis, maximum peak point, and $100 \%$ of lateral axis. This suggests that $o$-ABS and $p$-APA may not form a strongly bonded $1: 1$ charge-transfer complex, but mainly a $1: 1$ weak charge-transfer complex. Thus, it is considered that formation of the charge-transfer complex between $o$-ABS and $p$-APA occurs at first in the copolymerization of $p$-APA and $o$-ABS. Attack of the oxidant to the $1: 1$ charge-transfer complex will follow the complex forma-

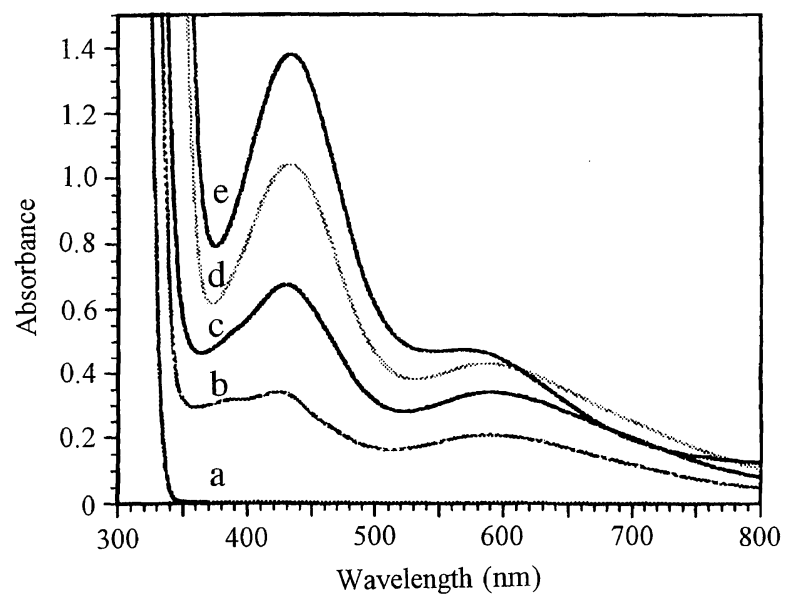

Figure 4. UV-Vis spectra of $p$-APA, $o$-ABS, and mixture of $p$ APA and $o$-ABS. Molar ratios of $p$-APA to $o$-ABS are (a) $0 / 1$, (b) $1 /$ 3 , (c) $1 / 1$, (d) $3 / 1$, and (e) $1 / 0$, respectively.

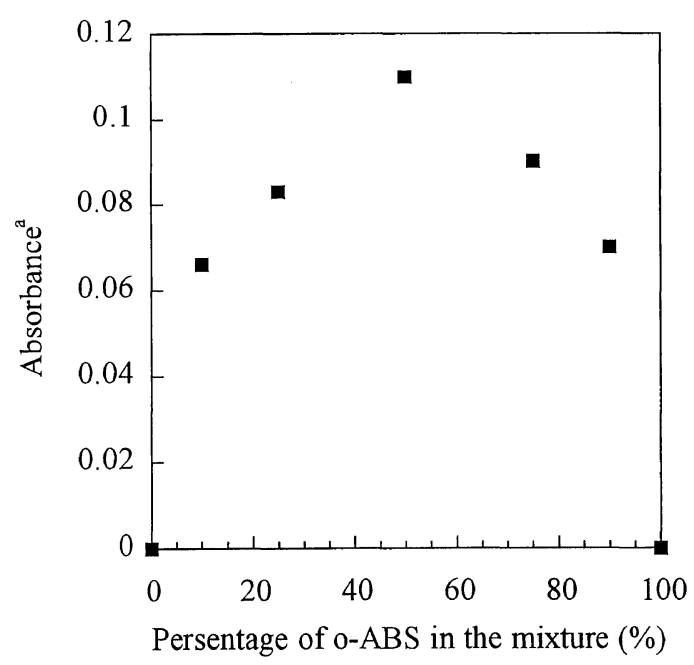

Figure 5. Correlation between the mole percentage of $o$-ABS in the mixture of $p$-APA and $o$-ABS and the absorbance of CT complex at $588 \mathrm{~nm}$. ${ }^{a}$ The absorbance was determined by subtracting the absorbance of the corresponding quantity of $p$-APA from the absorbance at $588 \mathrm{~nm}$ of spectra $\mathrm{b}$ to $\mathrm{d}$ in Figure 4 .

tion to produce the $1: 1$ copolymer of $p$-APA and $o$-ABS (Scheme 1). This mechanism could result in the present copolymer with moderate molecular weight.

\section{CONCLUSIONS}

The polymer yields in copolymerization at various charged mole ratios ( $p$-APA / $o$-ABS) have suggested the formation of the $1: 1$ copolymer between $p$-APA and $o$ ABS, because composition of the copolymer does not change in spite of increasing charged mole ratio of $o$ ABS to $p$-APA. In addition, elemental analysis, IR spectra, and ${ }^{1} \mathrm{H}$ NMR spectra of the synthesized copolymer indicate that the composition of the copolymer is $1: 1$. XPS spectra of the copolymer show that three kinds of nitrogen atoms exist in the copolymer as shown in Scheme 2, namely, amine nitrogen, radical cation type nitrogen introduced by self-doping, and iminium ions, and that one third of the whole nitrogens is self-doped. 


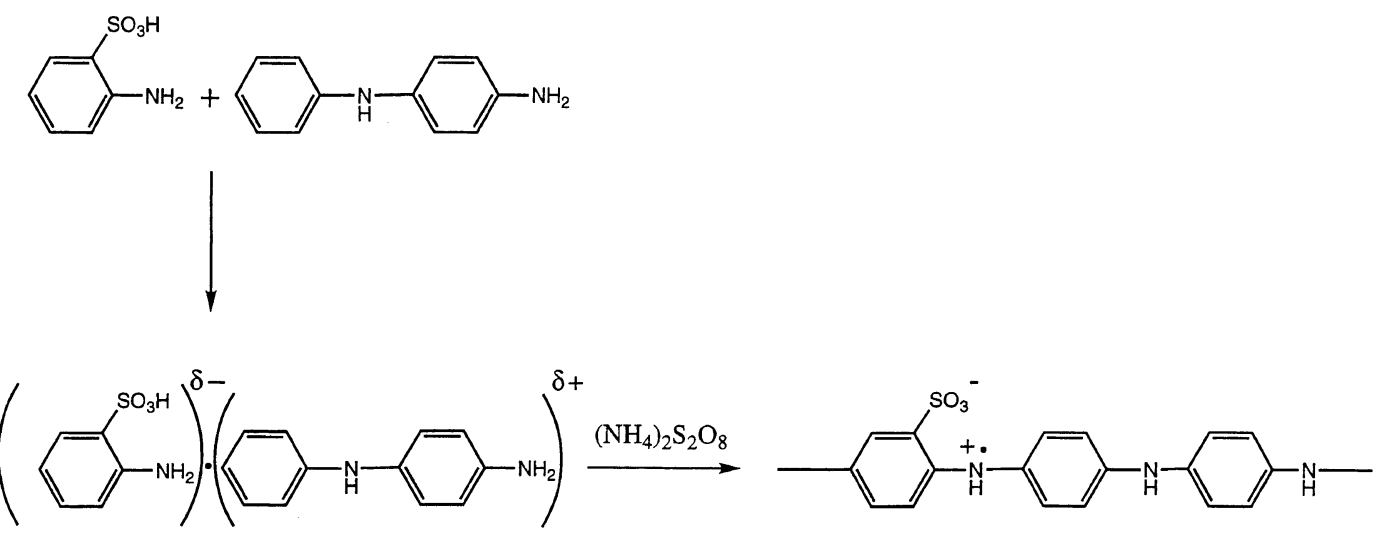

Charge-transfer complex

Scheme 1. Proposed mechanism for $1: 1$ copolymerization between $p$-APA and $o$-ABS.
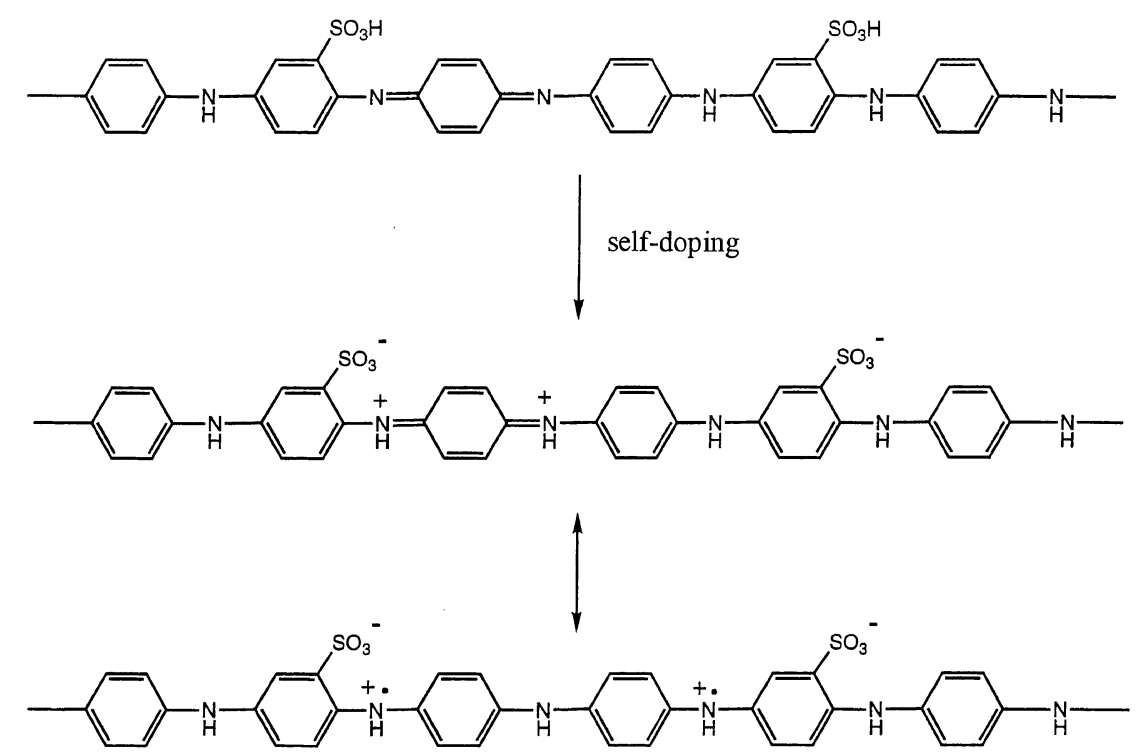

Scheme 2. Mechanism of self-doping by sulfonyl acid groups.

This result also supports the formation of the $1: 1$ copolymer.

The copolymer is soluble in an aqueous alkaline solution owing to the presence of sulfonyl acid groups. Conductivity of the copolymer is almost constant independent of $\mathrm{pH}$, but lower than that of doped-polyaniline probably because of electron-withdrawing capacity and steric hindrance of the sulfonyl group, which falls away from the polymer backbone at about $275^{\circ} \mathrm{C}$ as shown by the TGA measurement of the copolymer. UV-Vis spectra reveal that $p$-APA and $o$-ABS form the weak $1: 1$ chargetransfer complex. Based on these results, it is considered that the $1: 1$ weak charge-transfer complex forms at first in the copolymerization, and then the oxidant attacks this complex to form the $1: 1$ copolymer.

Acknowledgments. This work was supported by a Grant-in-Aid for Scientific Research (C) (No. 10650893) from the Ministry of Education, Science, Sports, and Culture, Japan.

\section{REFERENCES}

1. T. Nakajima and T. Kawagoe, Synth. Met., 28, C 629 (1989).

2. E. M. Genies, P. Hany, and C. Santier, J. Appl. Electrochem., 18, 751 (1988).

3. E. M. Genies, A. A. Syed, and C. Tsintavis, Mol. Cryst. Liq. Cryst., 121, 181 (1985).

4. M. Gholamian, J. Sundaram, and A. Q. Contractor, Langmuir, 3, 741 (1987).

5. M. Gholamian and A. Q. Contractor, J. Electroanal. Chem., 289, 69 (1990).

6. G. Mengoli, M. M. Musiani, G. Zotti, and S. Valcher, J. Electroanal. Chem., 202, 217 (1986).

7. M. Fabrizio, F. Furlanetto, G. Mengoli, M. M. Musiani, and F. Paolucci, J. Electroanal. Chem., 323, 197 (1992).

8. M. R. Anderson, B. R. Matters, H. Reiss, and R. B. Kaner, Science, 252, 1412 (1991).

9. K. Kaneto, W. Takashima, Y.-G. Min, and A. G. MacDiarmid, Synth. Met., 71, 2211 (1995).

10. P. Snauwaert, R. Lazzaroni, J. Riga, and J. J. Verbiest, Synth. Met., 21, 181 (1981).

11. S. K. Manohar, A. G. MacDiarmid, K. Kromack, J. M. Ginder, and A. J. Epstein, Synth. Met., 29, E 349 (1989). 
12. E. M. Genies, J. F. Penneau, and M. Lapkowski, New J. Chem., 12, 767 (1988)

13. D. L. Gin, V. P. Conticello, and R. H. Grubs, J. Am. Chem. Soc., 114, 3169 (1990)

14. N. Toshima, H. Yan, Y. Gotoh, and M. Ishiwatari, Chem. Lett., 1994, 2229.

15. H. Yan, H.-J. Wang, S. Sanggono, and N. Toshima, Bull. Chem. Soc. Jpn., 69, 2395 (1996).

16. J. Yue and A. J. Epstein, J. Am. Chem. Soc., 112, 2800 (1990).

17. J. Yue, A. J. Epstein, and A. G. MacDiarmid, Mol. Cryst. Liq. Cryst., 189, 255 (1990).

18. J. Y. Bergeron, J. W. Chevalier, L. H. Dao, J. Chem. Soc., Chem. Commun., 1990, 180.

19. J. Yue, Z. H. Wang, K. R. Cromack, A. J. Epstein, and A. G. MacDiarmid, J. Am. Chem. Soc., 113, 2665 (1991).

20. J. Yue and A. J. Epstein, Macromolecules, 24, 4441 (1991).

21. J. Yue, G. Gordon, and A. J. Epstein, Polymer, 33, 4410 (1992).

22. H. S. O. Chan, S. C. Ng, W. S. Sim, K. L. Tan, and B. T. G. Tan, Macromolecules, 25, 6029 (1992).

23. S.-A. Chen and G.-W. Hwang, J. Am. Chem. Soc., 116, 7939 (1994).

24. C. Barbero, M. C. Miras, B. Schynder, O. Haas, and R. Kötz, J. Mater. Chem., 4, 1775 (1994)
25. A. Kitani, K. Satoguchi, H.-Q. Tang, S. Ito, and K. Sasaki, Synth. Met., 69, 129 (1995).

26. S.-A. Chen and G.-W. Hwang, J. Am. Chem. Soc., 117, 10055 (1995).

27. S.-A. Chen and G.-W. Hwang, Macromolecules, 29, 3950 (1996).

28. S.-A. Chen and G.-W. Hwang, Polymer, 38, 3333 (1997).

29. H. Tang, A. Kitani, T. Yamashita, and S. Ito, Synth. Met., 96, 43 (1998).

30. M. Sudhakar, P. W. Stoceker, and T. Viswanathan, Recent Res. Dev. Polym. Sci., 2, 173 (1998).

31. J. Fan, M. Wan, and D. Zhu, J. Polym. Sci., Part A: Polym. Chem., 36, 3013 (1998).

32. S. Ito, K. Murata, S. Teshima, R. Aizawa, Y. Asako, K. Takahashi, and B. M. Hoffman, Synth. Met., 96, 161, (1998).

33. V. Prévost, A. Petit, and F. Pla, Synth. Met., 104, 79 (1999).

34. M.-Y. Hua, Y.-N. Su, and S.-A. Chen, Polymer, 41, 813 (1999).

35. P. Job, Ann. Chim., 9, 113 (1928).

36. W. C. Vosburgh and G. R. Cooper, J. Am. Chem. Soc., 63, 437 (1941).

37. J. Tang, X. Jing, B. Wang, and F. Wang, Synth. Met., 24, 231 (1988).

38. Y. Furukawa, F. Ueda, Y. Hyodo, I. Harada, T. Nakajima, and T. Kawagoe, Macromolecules, 21, 1297 (1988). 